\title{
'N OPNAME NA DIE EFFEKTIWITEIT VAN FISIOTERAPEUTIESE BEHANDELINGSMETODES VIR SKOUERGEWRIGTOESTANDE
}

E. Genis*

\section{OPSOMMING}

In hierdie projek is die resultate van twee metodes van fisioterapeutiese behandeting vir skouerpatologie met mekaar vergelyk. Twee groepe pasiënte is behandel: Groep A met passiewe mobilisasie volgens Mailland en Groep B met aktiewe oefeninge, ultraklank en dwarsfriksies. Uit die resultate blyk dit dat passiewe mobilisasie ' $n$ meer effektiewe metode is as die konserwatiewe behandelingsmetodes.

Van die belangrikste funksies van die komplekse skouergewrig is dié van stabiliteit en posisionering van die

\footnotetext{
* Uittreksel van project gedoen deur finale jaar student, Universiteit Stellenbosch.

Ontvang 25 Februarie 1982.
}

\section{SUMMARY}

In this project the results of two methods of physiotherapeutic treatment for shoulder paihology are compared. Two groups of parients were treated. Group A with passive mobilisation techniques according to Maitland and Group $B$ with active exercises, wlrasound and ransverse frictions. The results indicate that passive mobilisation is a more effective method of treatment than the conservative methods.

hand vir die hantering van voorwerpe. Dit is dus duidelik dat selfs 'n geringe beperking van die kompleks kan lei tot verlies van funksie.

Daar is egter so 'n wye verskeidenheid van oorsake van pyn in die skouerarea, terwyl die oorsprong so 'n groot variasie toon, dat dit soms moeilik is om 'n presiese diagnose

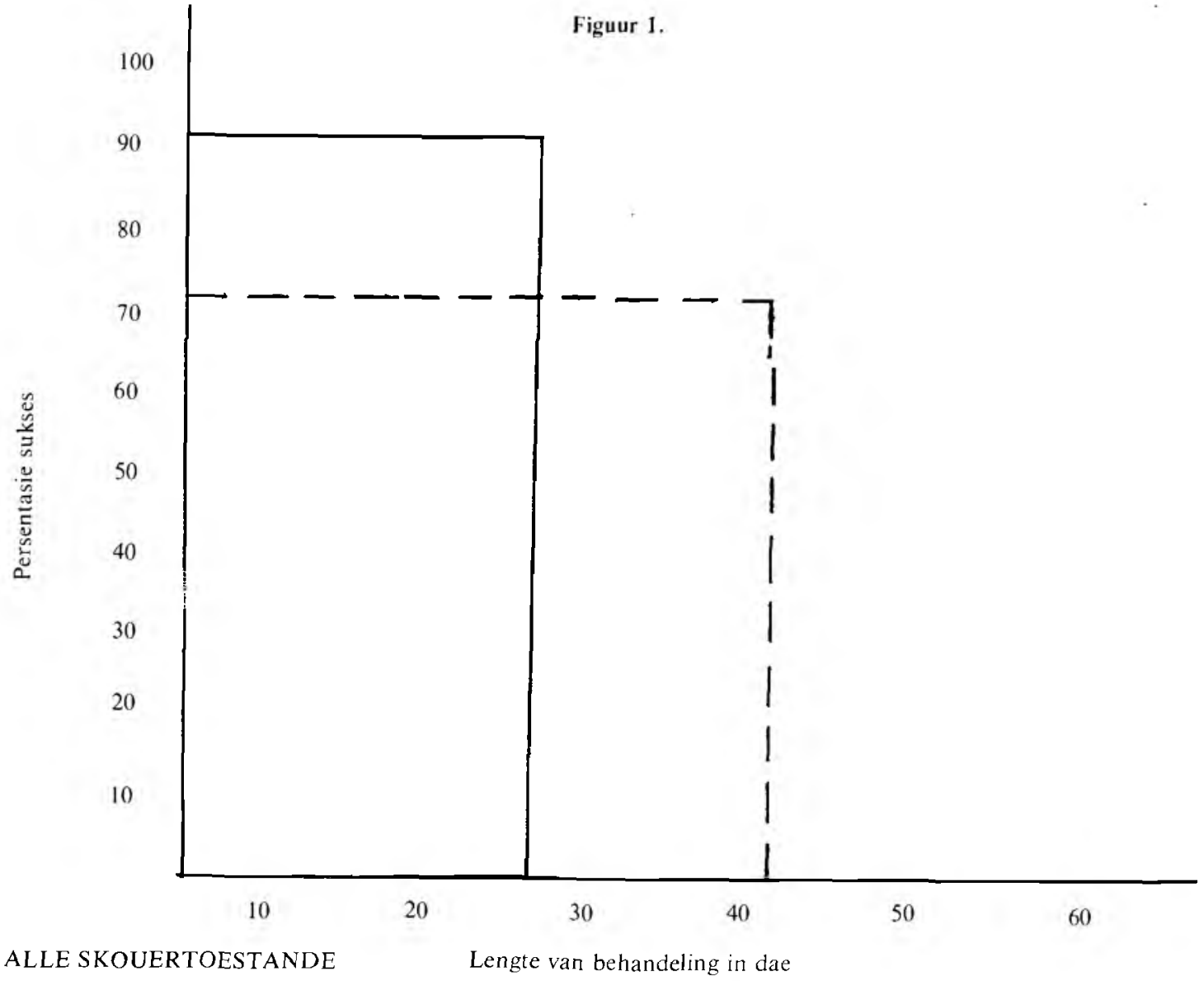

Groep a

---- Groep h 
Figuur 2.

Groep a

Groep b

\begin{tabular}{|c|c|}
\hline Aanial dae & Persentasie sukses \\
27,8 & 91,4 \\
43,7 & 72,8 \\
\hline
\end{tabular}

Figuur 3.

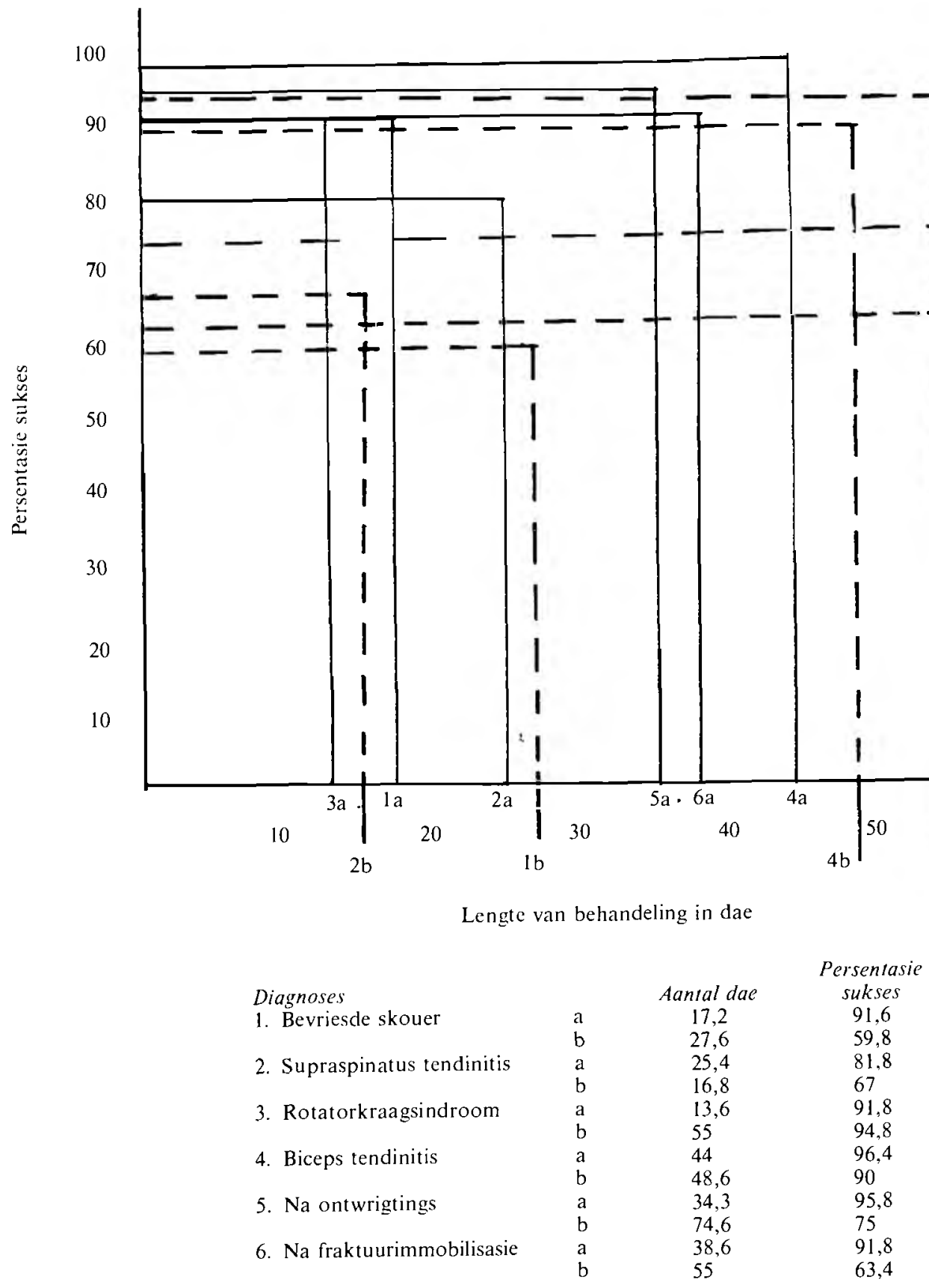


te maak. Dic grootste persentasie van alle pynlike gebreke is as gevolg van letsels van die muskulotendineuse kraag, bv. akute bursitis, tendinitis en vasklewende kapselitis. 'n Klein persentasie is as gevolg van osteo-artritis en ander toestande. Die rede hiervoor is die anatomiese rangskikking van die skouerarea, deurdat die stabiliteit van die gleno-humerale gewrig grootliks afhang van die tendons wat dit omring.

Die doel van hierdie projek was om 'n vergelykende studie op te stel tussen die fisioterapeutiese behandeling van skouergewrigtoestande deur middel van:

- passiewe mobilisasietegnieke volgens Maitland en

- konserwatiewe behandeling deur middel van aktiewe oefening, ultraklank, dwarsfriksies, ens.

\section{PROEFNEMING}

'n Steek proef van pasiënte, verwys deur geneeshere vir die behandeling van skouergewrigtoestande, is geneem gedurende die tydperk Januarie 1979 tot Junie 1980. Slegs 52 van die totale 140 pasiënte het aan die kriterium, opgestel vir die projek, voldoen.

Die steekproef is vervolgens gegroepeer volgens hulle tekens en simptome onder die diagnoses:

1. Bevriesde skouer.

2. Supraspinatus tendinitis.

3. Biceps tendinitis.

4. Rotatorkraag-sindroom.

5. Herhaalde ontwrigting met operatiewe herstel.

6. Immobilisasie na 'n fraktuur.

Die 52 pasiënte is verder in twee groepe verdeel. Groep A. bestaande uit 28 pasiënte, hel fisioterapeutiese behandeling ontvang deur middel van passiewe mobilisasie volgens Maitland en groep B bestaande uit 24 pasiënte, het konserwatiewe behandeling ontvang.

Die effektiwiteit van die fisioterapeutiese behandeling is geëvalueer deur middel van die volgende sisteem:

- Pasiënt.

- Diagnose.

- Tekens en simptome.

- Behandeling.
- Effekte

- Aantal behandelings volgens dae.

- Persentasie sukses.

Die persentasie sukses is bepaal in terme van herwinning van normale funksie, dit wil sê pynvrye volle omvang.

\section{Resultate}

Tabelle is opgetrek waarin die aantal behandelings in dae teenoor dic persentasie sukses van groep A met groep B vergelyk word. Die gemiddeldes is daarna bepaal en hierdie twee veranderlikes grafies voorgestel. (Fig. 1).

Daar is dus 'n verskil van 16 dae en $18 \%$ tussen die twee groepe. (Fig. 2.) Die gemiddeldes van die 6 diagnoses is onderling ook bepalal en grafies voorgestel. (Fig. 3).

\section{GEVOLGTREKKING}

Met verwysing na die tabelle en grafiese voorstellings, is dit duidelik dat groep $A$ in ' $n$ korter periode van fisioterapeutiese behandeling 'n groter persentasie sukses behaal het. Passiewe mobilisasie volgens G. D. Maitland as 'n metode om skouertoestande te behandel, is dus meer effektief as die meer konserwatiewe metodes.

\section{Bibliografie}

Bain, A. M. (1971). Supraspinatus tendinitis, Physiother., 57, 17-20.

Brookes, R. B. (1971). Physiotherapy treatments of supraspinatus tendinitis. Physiorher., 57, 21-23.

Cash. J. E. (Ed.) (1976). A Textbook of medical conditions for Physiotherapists. 5th Ed. Faber Faber. London.

Maitland, G. D. (1974). Relating passive movement to some diagnoses, Aust. J. Physiother., 20, 129-135.

Maitland, G. D. (1973). The treatment of joints by passive movement, Aust. J. Physiother., 19, 65-72.

Maitland, G. D. (1971). The treatment of the glenohumeral joint by passive Movement, Physiother., 57, 261-267. 